\title{
"Quiero con mi atrevimiento" \\ Textualidad y rebeldía en Julieta Kirkwood
}

\section{Raquel Olea ${ }^{1}$}

\author{
"Y pensaba en dos libros, en dos tomos; \\ uno muy ordenado de ideas y \\ otro de tiempos: la historia, las historias."
}

Julieta Kirkwood

La insatisfacción política que nos ha deparado la "transición" sumada a la fagocitación capitalista en que se desarrolla el pensamiento actual, nos obliga a volver una y otra vez la mirada hacia ciertas figuras y palabras que resuenan como promesas de rebeldías en un tiempo donde no queremos dejar de pensar que ésta sigue siendo posible. En esa memoria se sitúa privilegiada la textualidad de Julieta Kirkwood, socióloga y fundadora del Movimiento Feminista en Chile en 1983.

Hoy dispersada la cohesión política y la significación social que en otro tiempo tuvo el movimiento feminista, perdidas las preguntas y el discurso que intentaba responderlas, los textos de Kirkwood permanecen plenos de rendimiento e interrogan nuestra lectura con una productividad dirigida, con la misma insistencia de entonces, a las prácticas de la palabra y de la política. El movimiento feminista de los años ochenta marcó el lugar de las mujeres, como sujetos políticos, inaugurantes de producción de un saber nuevo y de las relaciones de esas prácticas de saber/poder con los saberes/poderes históricamente legitimados y escuchados socialmente.

Julieta Kirkwood fue quien primero advirtiera en el feminismo chileno de la década de los 80's la necesidad de producir teoría feminista, pero, a su juicio, ésta debía producirse desde la práctica política de las mujeres, desde la necesidad de hacer de lo cotidiano y lo organizacional un material reflexivo en la construcción de conocimiento y pensamiento feminista; así lo 
dice: "En Chile el movimiento feminista es apenas emergente y no ha tenido aún el tiempo de teorizar" (Kirkwood 1986). Motivada por esa necesidad, Kirkwood conjugó acción y reflexión dejando un legado textual de producción teórica. Sus textos constituyen una fuente de múltiples interrogantes culturales, políticas y disciplinarias que no han perdido su vigencia y que de tiempo en tiempo se hace necesario revisitar. Pensar en democracia lo que Julieta construyó en dictadura nos vuelve a conectar con problemas políticos más profundos y asentados en los imaginarios culturales y políticos y que insistentemente vuelven a emerger como síntomas de un "nudo" en las relaciones de género en la actual coyuntura política.

El trabajo de Julieta K. se desarrolla en dos grandes áreas: una que relaciona a las mujeres con la producción de saber y otra que las sitúa en la compleja relación que las mujeres establecen con el poder y la política, pero también se refiere a las relaciones que la sociedad establece con el saber y el poder de las mujeres. En ambos campos, el de la política y el del saber, Kirkwood deja notar que ella trabaja en un estado de malestar. Por una parte, su procedencia disciplinaria, la lengua teórica de la sociología, en la que debe hablar como teórica, le exige una coherencia que la pone en permanente tensión con la voluntad de teorizar desde la práctica feminista, su práctica feminista. Pero será en el intersticio de esa dualidad donde paradojalmente emerge su particular modo de decir, es decir, donde se hace necesaria la proposición de otra lengua para elaborar la experiencia política feminista. Los sentidos de su palabra se juegan en parte en la certeza de su voluntad teórica, pero también en el malestar a que le obliga la coherencia de la lengua teórica como exigencia de esa voluntad. Es en el intersticio de esa dualidad donde emerge furtivamente un modo de decir que propone una lengua feminista. La escritura se construye doblemente fiel a la necesidad de teorizar la historia de las mujeres y a la desazón en el lenguaje que al decir, debe situar su registro en el afuera de su particular lugar de habla y de la forma que requiere para (su) decir. 


\section{Cuerpo textual v/s cuerpo biográfico}

Uno de los aportes más significativos de Kirkwood a la producción crítica es su reflexión respecto a la (im)potencia de la lengua de las ciencias sociales para decir la complejidad de su compromiso político-feminista: "Y pensé: no habré de dar tantas explicaciones traducidas penosa y dificultosamente al plano de la lógica, del razonamiento sociológico; a lo obvio de categoría universal. Así cumpliré con el feminismo" (Kirkwood 1986).

Su escritura se produce así, atrapada y entrampada entre la disciplinariedad que le impone el cientificismo sociológico y la indisciplina de su específica posición, el feminismo. Su texto es la producción de un doblez de lenguajes de otro lugar que se traman, asimismo, a su cuerpo biográfico, haciendo de ambos, un depósito de signos situados en el específico espacio de la historia de Chile en dictadura, con la expectativa de llevar a cabo transformaciones radicales. La materia de su cuerpo no resistió la empresa, Kirkwood murió antes del tiempo de su palabra, en 1985.

El cuerpo textual ha quedado como indicio y legado de un registro crítico innovador que busca responder a su deseo de abrir la investigación científica a la historia de las mujeres y de abrir la historia a una lengua articuladora del compromiso que la sostiene. En la intención de ese compromiso, Kirkwood elabora una lengua de rebeldía y se debate, como ella dice, "en producir dos libros, dos tomos, uno muy ordenado de ideas y otro de tiempos" (Kirkwood 1986). El resultado es un texto que articula su potencia en ese hiato, entre la historia y los tiempos, aludiendo con esto último a una diferencia situada también en la relación de las mujeres con el tiempo.

Estos planteamientos de Kirkwood tienen su presencia concreta en las interrupciones del texto, en sus fisuras y en los cambios de registro y de lengua que constituyen su materialidad. En esta oportunidad intento situarme en ese intersticio para leer la insatisfacción, pero también el potencial de su lengua. Julieta habla a destiempo, a ratos buscando un sitio en la ciencia, ganándolo, haciéndoselo en el discurso fuerte, dicho en voz alta, reclamando un derecho a la escucha disciplinaria; a ratos produciendo un texto poético, replegado, acallado, de voz baja, que 
punto a punto teje el nudo de lenguajes que el propio texto enuncia como hallazgo, "me faltaba la línea multiplicada que pudiera converger este atochamiento de letras. Usé otro estilo. Hice mi descubrimiento más querido: los nudos feministas" (Kirkwood 1986). Así nombra el enunciado que articula la productividad simbólica de un atascamiento en el lenguaje.

Ambos lenguajes, el de la historia y los tiempos, el de la disciplina y el de la práctica política, superponen en sus pliegues la producción de un texto movedizo, inclasificable que pone a prueba un excedente de sentido en el que traduce su máxima riqueza. Kirkwood produce un texto dentro de otro; texto ilegítimo, bastardo que alterna en la escritura preguntas y perplejidades para su lugar en la genealogía y en los discursos del saber.

\section{Lengua feminista}

Inscrita mayoritariamente en el feminismo y en la disciplina sociológica -como pariente pobre- la escritura de Julieta K. comparece hoy en el lugar histórico de un cruce, de una potencialidad de producción teórica y política que emerge de la concepción de un compromiso que ella articuló como su rebeldía feminista.

Filiada a la noción de compromiso como conjunción de la práctica teórico-política y de existencia, Kirkwood refiere esta idea a Sartre para producir una "investigación comprometida," en el sentido de "destacar las contradicciones entre la universalidad de los supuestos científicos del conocimiento propuestos por la cultura dominante, y la particularidad que asumen las experiencias" (Kirkwood 1986). Será el re-conocimiento de la imposibilidad de esa investigación sociológica desde el feminismo, lo que le posibilitará abrir el otro y que dará curso al lenguaje de la rebeldía, "estoy abordando una investigación larga y rara [...] preciso este punto, pues de ahí derivan impresionantes faltas de precisión y no menos impresionantes pruebas vivenciales de lo que en el lenguaje intento explicar" (Kirkwood 1986).

Julia Kristeva se pregunta por el sentido que puede tener la rebeldía en la actualidad, en medio de una cultura gobernada por el relativismo de las imágenes y por la indiferencia que ha impuesto el valor de lo monetario. La rebeldía, dice, "tuvo lugar, 
no ha sido borrada; se da a leer y se le dará cada vez más a leer a una humanidad descarriada." Al revisar esas potencialidades actuales, Kristeva (Kristeva 2000) se detiene en algunas etimologías que puedan ser pertinentes para una resignificación del concepto y que permiten articularlas al pensamiento de Kirkwood. Entre las significaciones de rebeldía, ésta quiere decir las de entorno, vuelco, retorno, envolver, enrollar, las que podrían traerse al presente y situarla con nuevo sentido. Desde otra perspectiva, Kristeva trabaja la rebeldía desde el punto de vista psicoanalítico para recordarnos que según los modelos freudianos del lenguaje las nociones de poder y de interdicto remiten a la figura paterna; al asesinato del padre y a la institución del interdicto simbólico. Esto quiere decir que para cada ser humano la función paterna o la función de autoridad se encuentra dada en nuestra aptitud para el lenguaje: las normas de los lenguajes, sus demarcaciones disciplinarias, sus referencias formalizadas desde las institucionalidades del poder, desde las categorizaciones genéricas hasta las leyes de la gramática y el uso de figuras y retóricas codificadas para los distintos tipos de discursos, estarían dando cuenta de esta relación con la autoridad a que nos somete el uso del lenguaje.

La referencia sitúa, sin duda, la rebeldía en relación a las normativas de los lenguajes como posición de resistencia a la función de la autoridad paterna que se refleja en la posición que se tiene frente a uno de los lazos que nos constituyen. La relación con los mandatos del lenguaje abre un flanco para mirar una condición de la rebeldía que articula una práctica política desde un sujeto que incursiona en el discurso, pero no acepta su normativa. ¿Quién se rebela, y contra qué? es la interrogante que me aproxima al texto de Kirkwood.

La producción central de J. Kirkwood está dada por su libro Ser política en Chile. Lugar marginal ocupa una producción reflexiva y poética, reunida en un texto fragmentado de difícil clasificación publicado bajo el nombre Tejiendo rebeldias. Ambos fueron editados póstumamente por sus compañeras del movimiento feminista. Ser politica en Chile. Las feministas y los partidos fue publicado por FLACSO en 1986, un año después de su muerte.Tejiendo rebeldías haría productiva la significación del nudo como signo en que se juntan los hilos de un promisorio 
despliegue de figuras para una sujeto mujer, en tanto tramado de saberes múltiples.

Desde las primeras líneas de Ser politica en Chile, J. Kirkwood establece una pugna en el lenguaje. En el centro de su textualidad se agazapa bajo distintos signos la pregunta recurrente que sitúa problemáticamente su escritura en relación a los lenguajes legitimados de las ciencias sociales; una incerteza, una inquietud obligan a la autora a iniciar su texto con una introducción titulada "Por qué este libro y el rollo personal," donde enuncia su preocupación en torno a la necesidad de historizar, pero también de poner su propia subjetividad como objeto de la reflexión teórica, "no ser extraña a la historia es no ser extraña tampoco a la formación del conocimiento y la ciencia." La voluntad de Kirkwood investigadora, precisa dos necesidades, la de historizar, y pertenecer al campo del saber, pero también marca la necesidad de efectuar la distinción entre feministas y políticas. Es en la dicotomía entre política partidista y feminismo donde sitúa, para su trabajo, un primer impasse en el lenguaje. Teorizar la política se hace posible para ella en un campo de trabajo que cuenta con tradición, disciplina metodológica y modelos establecidos, es en el campo del feminismo donde le asalta una mudez particular por la falta de inscripción de las mujeres, y de la historia de las mujeres en el campo del pensamiento, ésta, la primera rareza del texto, plantea de entrada una escisión en la lengua. Su posición de feminista la sitúa en el lugar raro, de lo sin demarcaciones de método, ni de lenguaje.

Kirkwood procede de una formación teórica sociológica en una época donde las lecturas de Weber, Marx eran las más frecuentes. Su relación con la noción de compromiso está explicitada en las citas de Sartre, Camus, Beauvoir; su pensamiento feminista surge mayoritariamente en la discusión política del momento histórico de la dictadura donde se extrema la tensión entre militancia partidista y autonomía feminista. Kirkwood en su texto va optando, va deshaciendo ese "nudo," para situarse en un habla que escinde el texto y lo construye.

La rebeldía de Kirkwood es intervenir el texto sociológico y producir un texto de fusión, que diera cuenta de la historia y de la experiencia, la historia y el tiempo. En el intersticio de su producción se instala una disputa interna que vuelca el texto 
hacia una dificultad interior, produciendo un texto de entremedio, una inestabilidad productiva. La inserción de la subjetividad en el lenguaje de las ciencias abre una fisura. Esto connota de una particularidad que lo hace escabullir las clasificaciones que lo situarían con certeza en lo disciplinariamente marcado y que, por otra parte, le otorga al texto científico marcas que lo desvían de los géneros de las ciencias sociales. Ambas estrategias textuales se cruzan y se desplazan subrepticiamente en la escritura.

La enunciación de lo que ella llamó "el rollo personal" se constituye en el despliegue de una estrategia que desde lo débil de una desidentidad se hace fuerte en el transcurso escritural, en el goce de introducir un material que asalta la lectura con la irrupción y la insolencia propia de quien se rebela a los mandatos, a un determinado modo de escribir, apoderándose de un resquicio textual que le posibilita decir lo que el lenguaje adscrito a las metodologías científicas no le permitiría. Escribe, "me faltaba la línea multiplicada que pudiera converger este atochamiento de letras," "ensayando suavidad y huecos, palabras femeninas, dije lo que había que decir."

La construcción de una textuatidad envolvente, originada en la fusión de diversos modos de decir, produce la rareza de una investigación sin filiación fija, sin genealogía definida que vuelca el lenguaje de las ciencias sociales por la introducción de secretos, silencios, tonalidades y ritmos de lenguaje que protegen y nutren la investigación disciplinaria para interrumpir la linealidad de la lógica de ese lenguaje (el de la sociología) que nombra su producción.

La construcción de un texto plural, de fusión, de escisiones, de la experiencia política del compromiso feminista constituye, a mi juicio, el mayor interés de una investigación que elabora su mayor provocación y rebeldía en ese doblez, en ese cruce textual. Su gesto cohesiona su proyecto teórico-crítico al nombrar y decir lo que la ciencia no puede decir, no por prohibición sino por estar impedida para ello, por el handicap de la lengua teórica-objetiva del intelectual comprometido sartreano que ella enunció como modelo y que su propia escritura ha desplazado, apartándola del sujeto universal de ese proyecto teórico-crítico.

Con el gesto de interrumpir la historia de dominación del lenguaje científico, la autora pone en escena su verdadero lugar 
teórico; los lenguajes científicos y su pretendida neutralidad restringen e imponen una ausencia de la experiencia coma materia del texto, que en el "compromiso" de Kirkwood resultaría inaceptable, su rebeldía la obliga a ocupar la dualidad, la del habla fuerte de la ciencia y el habla baja de la experiencia, del silencio que constituyen en el texto los signos de su resistencia a la estridencia de la lengua única de la oficialidad del saber, pero también al silencio histórico de las mujeres.

Kirkwood ha intervenido con su "decir bajito" la lengua del poder para inocular en su texto aquello que no puede decir en la voz fuerte de la lengua que públicamente la constituye como sujeto de investigación científica, es su manera ladrona de introducir el decir feminista, decir que inestabiliza el decir de las ciencias y su propia condición de sujeto teórico. Amparada en una desidentidad, Kirkwood se cubre con la lengua de la ciencia, pero la burla para introducir la falta de lenguaje feminista que se articula como voz tenue, como risa, como silencio y recurrencia al imaginario del cuerpo. Kirkwood extrema su malestar en la lengua hasta el punto que en el transcurso del texto éste se vuelve un goce rebelde que se impone, al enunciar, ya al final de éste una escena de cuerpos que exagera la impotencia de la lengua disciplinaria para nombrar "una escritura propia cuya propiedad se sitúa en el cuerpo." "Y en un nuevo golpe de párpado la potencialidad del sexo, placer del juego [...], la gestualidad descohibida, las nuevas viejas muecas -el dolor y la Cara- vuelta carcajada." La afasia de la lengua científica es aquí constatada y cotejada con el poder de una palabra emanada de la materia misma de lo femenino. Kirkwood no tiene otra alternativa que situarse en un desplazamiento, una combinatoria, un juego de signos que extrema la singularidad de su propio decir y de su diferencia.

La rebeldía de Kirkwood se marca por la inflexión distorsionadora de los códigos de autoridad de la lengua de las ciencias sociales de su tiempo, o al menos para la producción en su propio texto, de una interrupción donde la irrupción de un habla que articula, en la enunciación de una gestualidad corporal, una polifonía que la filia a la lengua carnavalesca, pluraliza su texto con la introducción de una poética política: “¿qué otra cosa si no, es plantear la incorporación triunfal de la fiesta 
a una sociedad generada, planteada y administrada en forma lúgubre?" Kirkwood hablaba, por cierto de la lobreguez de la dictadura, pero hoy, en el glamour neo-liberal y su vaciamiento del lenguaje, su rebeldía vuelve a dejarse oír.

En esta posmodernidad dura a que nos obliga el neoliberalismo donde las causas no parecen tener lugar, el texto de Kirkwood presenta un potencial político que, en sus proposiciones de rebeldía contra los lenguajes oficiales del saber y el poder, inició la desatadura de un nudo que hace posible pensar históricamente el habla de la experiencia y de la práctica política con el estatuto teórico que compromete al sujeto con la rebeldía en el lenguaje. Ése fue su atrevimiento.

\section{Nota}

1 Doctora en literatura de la Universidad W. Goethe de Frankfurt, Alemania. Ha publicado libros y diversos artículos en revistas nacionales e internacionales. Co-productora y conductora de programas radiales sobre literatura en Radio Tierra. Presidenta de la Corporación de Desarrollo de la Mujer La Morada.

\section{Bibliografía}

Kirkwood, Julieta. Ser política en Chile. Las feministas y los partidos. Santiago de Chile: Flacso, 1986.

Kristeva, Julia. Sentido y sinsentido de la rebeldía. Literatura y psicoanálisis. Santiago de Chile: Cuarto Propio, 2000. 